\title{
Primary Ear and Temporal Bone Meningiomas: A Clinicopathologic Study of 36 Cases with a Review of the Literature
}

\author{
Lester D. R. Thompson, M.D., John-Paul Bouffard, M.D., Glenn D. Sandberg, M.D., \\ Hernando Mena, M.D. \\ Departments of Endocrine and Otorhinolaryngic-Head \& Neck Pathology (LDRT) and Neuropathology and \\ Ophthalmic Pathology (JPB, GDS, HM), Armed Forces Institute of Pathology, Washington, D.C.
}

\begin{abstract}
"Primary" ear and temporal bone meningiomas are tumors that are frequently misdiagnosed and unrecognized, resulting in inappropriate clinical management. To date, a large clinicopathologic study of meningiomas in this anatomic site has not been reported. Thirty-six cases of ear and temporal bone meningiomas diagnosed between 1970 and 1996 were retrieved from our files. Histologic features were reviewed, immunohistochemical analysis was performed $(n=19)$, and patient follow-up was obtained $(n=35)$. The patients included 24 females and 12 males, aged 10-80 years (mean, 49.6 years), with female patients presenting at an older age (mean, 52.0 years) than male patients (mean, 44.8 years). Patients presented clinically with hearing changes $(n=20)$, otitis $(n=7)$, pain $(n=5)$, and/or dizziness/vertigo $(n=3)$. Symptoms were present for an average of $\mathbf{2 4 . 6}$ months. The tumors affected the middle ear $(n=25)$, external auditory canal $(n=$ 4), or a combination of temporal bone and middle ear $(n=7)$. The tumors ranged in size from 0.5 to $4.5 \mathrm{~cm}$ in greatest dimension (mean, $1.2 \mathrm{~cm}$ ). Radiographic studies demonstrated a central nervous system connection in 2 patients. Histologically, the tumors demonstrated features similar to those of intracranial meningiomas, including meningothelial $(n=33)$, psammomatous $(n=2)$, and atypical $(n=1)$. An associated cholesteatoma was identified
\end{abstract}

Copyright () 2003 by The United States and Canadian Academy of Pathology, Inc.

VOL. 16, NO. 3, P. 236, 2003 Printed in the U.S.A.

Date of acceptance: December 7, 2002.

Presented at the 91st Annual Meeting of the United States and Canadian Academy of Pathology, Chicago, Illinois, February 23-March 1, 2002.

The opinions or assertions contained herein are the private views of the authors and are not to be construed as official or as reflecting the views of the Department of Army, the Department of the Air Force, or the Department of Defense.

Address reprint requests to: Lester D.R. Thompson, M.D., Department of Endocrine and Otorhinolaryngic-Head \& Neck Pathology, Building 54, Room G066-11, Armed Forces Institute of Pathology, 6825 16th Street, NW, Washington, DC 20306-6000; fax: 202-782-3130; e-mail: thompsonl@afip.osd.mil.

DOI: 10.1097/01.MP.0000056631.15739.1B in 9 cases. Immunohistochemical studies confirmed the diagnosis of meningioma with positive reactions for epithelial membrane antigen (79\%) and vimentin $(100 \%)$. The differential diagnosis includes paraganglioma, schwannoma, carcinoma, melanoma, and middle ear adenoma. Surgical excision was used in all patients. Ten patients developed a recurrence from 5 months to 2 years later. Five patients died with recurrent disease (mean, 3.5 years), and the remaining 30 patients were alive $(n=25$, mean: 19.0 years) or had died ( $n=5$, mean: 9.5 years) of unrelated causes without evidence of disease. We conclude that extracranial ear and temporal bone meningiomas are rare tumors histologically similar to their intracranial counterparts. They behave as slow-growing neoplasms with a good overall prognosis (raw 5-y survival, 83\%). Extent of surgical excision is probably the most important factor in determining outlook because recurrences develop in $28 \%$ of cases.

KEY WORDS: Adult, Ear, Histology, Immunohistochemistry, Meningioma, Prognosis, Temporal bone. Mod Pathol 2003;16(3):236-245

Meningioma is a common intracranial neoplasm (15-18\%) with a variety of histomorphologic growth patterns that are usually easily recognized $(1,2)$. However, primary extracranial (ectopic, extracalvarial) meningiomas of the ear and temporal bone are rare, making up $<1 \%$ of all meningiomas. The literature is generally limited to isolated case reports (2-38), with a few literature reviews $(2,9,36$, 39). The largest study to date includes 14 cases but only describes a single case that does not have an intracranial component (2). Controversy continues to exist around the exact origin of ear and temporal bone meningiomas $(10,39)$. Histologically, meningiomas of the ear and temporal bone are identical to their intracranial counterparts, although diagnostic difficulties because of the rarity of meningi- 
omas in this location are frequently encountered in the differential diagnosis with paraganglioma, schwannoma, middle ear adenoma (carcinoid tumor), carcinoma, and melanoma. We studied 36 cases of primary ear and temporal bone meningiomas to describe the clinical findings associated with these tumors, illustrate their pathologic features, document their immunophenotype, apply meningioma grading parameters as proposed by the World Health Organization Classification of Brain Tumors (40), and analyze these data as they relate to patient outcome in a single comprehensive study. Our results are analyzed in comparison to a review of the English literature.

\section{MATERIALS AND METHODS}

The records of 36 patients with tumors diagnosed as meningiomas primarily involving the ear and temporal bone without an obvious intracranial tumor mass or initial central nervous system connection were selected. The cases were retrieved from the files of the Otorhinolaryngic-Head \& Neck Tumor Registry of the Armed Forces Institute of Pathology (AFIP), Washington, DC, between 1970 and 1996. These 36 cases were chosen from a review of $1771(2.0 \%)$ benign or malignant primary ear and temporal bone tumors seen in consultation during this time.

Materials within the Institute's files were supplemented by a review of the patient demographics (gender, age); symptoms and physical findings and duration at presentation, including mass, hearing loss, bleeding, infection, pain, headaches, weakness, syncope or dizziness, nerve paralysis, discharge, equilibrium changes, tinnitus and/or popping, and visual changes; and medical and surgical history (specifically related to the ear and temporal bone and regarding the presence of neurofibromatosis). In addition, we reviewed radiographic, surgical pathology, and operative reports and obtained follow-up information from oncology data services by written questionnaires or direct communication with the treating physicians or the patient. Follow-up data, available for all patients, included information regarding tumor location, presence of recurrent disease, treatment modalities used, and current patient status. This clinical investigation was conducted in accordance and compliance with all statutes, directives, and guidelines of the Code of Federal Regulations, Title 45, Part 46, and the Department of Defense Directive 3216.2, relating to human subjects in research.

The macroscopic pathology observations noted within this study were gathered from the individual gross descriptions of the neoplasms given by the contributing pathologists. Hematoxylin and eosinstained slides from all cases were reviewed to confirm the diagnosis of meningioma. Meningiomas were classified according to subtype based on the World Health Organization 2000 criteria (40). Lesions were considered atypical if they possessed a mitotic rate of more than four per 10 high-power fields $\left(2.5 \mathrm{~mm}^{2} ; 41,42\right)$ and/or had at least three of the following histologic features: hypercellularity, growth of tumor cells in sheets, prominent nucleoli, necrosis, and small cell formation (43).

Immunophenotypic analysis was performed in 19 cases with suitable material. The standardized avidin-biotin method of Hsu et al. (44) was used, using 4- $\mu \mathrm{m}$-thick, formalin-fixed, paraffinembedded sections. Table 1 documents the pertinent commercially available immunohistochemical antibody panel used. The analysis was performed on a single representative block in each case. When required, proteolytic antigen retrieval was performed with predigestion for 3 minutes with $0.05 \%$ Protease VIII (Sigma Chemical Co, St. Louis, MO) in a $0.1 \mathrm{~m}$ phosphate buffer at a $\mathrm{pH}$ of 7.8 , at $37^{\circ} \mathrm{C}$. Antigen enhancement (recovery) was performed, as required, using formalin-fixed, paraffin-embedded tissue treated with a buffered citric acid solution and heated for 20 minutes in a calibrated microwave oven. After this, the sections were allowed to cool at room temperature in a citric acid buffer solution for 45 minutes before the procedure was

TABLE 1. Immunohistochemical Panel

\begin{tabular}{|c|c|c|c|c|}
\hline Antigen/Antibody & Primary Antibody & Company & Dilution & Antigen Recovery \\
\hline Epithelial membrane antigen (EMA) & $\mathrm{mm}$ & Dako, Carpinteria, CA & $1: 100$ & Protease digestion \\
\hline Glial fibrillary acidic protein (GFAP) & rp & DAKO & $1: 2000$ & Protease digestion \\
\hline S-100 protein & $\mathrm{rp}$ & DAKO & $1: 800$ & $\mathrm{n} / \mathrm{a}$ \\
\hline Vimentin & $\mathrm{mm}$ & BioGenex Labs, San Ramon, CA & $1: 400$ & $\mathrm{n} / \mathrm{a}$ \\
\hline Cytokeratin (AE1/AE3 and CK1) & $\mathrm{mm}$ & $\begin{array}{l}\text { Biochemicals, Indianapolis, IN, } \\
\text { and DAKO }\end{array}$ & $1: 200$ & Protease treatment \\
\hline CAM5.2 & $\mathrm{mm}$ & Ventana, Tucson, AZ & $1: 100$ & Protease digestion \\
\hline CK20 & $\mathrm{mm}$ & DAKO & $1: 50$ & Protease digestion \\
\hline CK7 & $\mathrm{mm}$ & DAKO & $1: 200$ & Protease digestion \\
\hline Chromogranin & $\mathrm{mm}$ & DAKO & $1: 100$ & $\mathrm{n} / \mathrm{a}$ \\
\hline Synaptophysin & rp & DAKO & Neat & Protease digestion \\
\hline Synuclein & $\mathrm{mm}$ & Novacastra, New Castle, UK & $1: 80$ & Microwave \\
\hline Ki67 & $\mathrm{mm}$ & Immunotech, Westbrook, ME & $1: 20$ & Microwave \\
\hline
\end{tabular}

mm: mouse monoclonal; rp: rabbit polyclonal. 
continued. Standard positive and negative (serum) controls were used throughout. The antibody reactions were graded as weak $(1+)$, moderate $(2+)$, and strong $(3+)$ staining, and the fraction of positive cells was determined by separating the percentage of positive cells into four groups: $<10 \%$, $10-50 \%, 51-90 \%$, and $>90 \%$, specifically for the proliferation marker (Ki-67).

A review of English-language publications (MEDLINE years 1966 to 2002) was performed, and all cases primarily involving the ear and temporal bone were included in the review. Cases that involved only the skin overlying the temporal bone, orbit, oral cavity, nasal cavity, nasopharynx, sinuses, or soft tissues of the neck were excluded.

\section{RESULTS}

\section{Clinical}

The patients included 24 females and 12 males (Table 2). Their ages ranged from 10 to 80 years, with an overall mean age at presentation of 49.6 years (median, 51 years). The average age at presentation for women was older than that for men: 52.0 and 44.8 years, respectively, which was statistically significant $(P=.01)$. Patients most frequently presented with hearing changes $(n=20)$, either sensorineural or conductive. Other symptoms included otitis, headaches, dizziness, unsteadiness, vertigo, disequilibrium, tinnitus, otalgia, bleeding, "metallic taste," and a chronic cough (Table 2). Facial or other cranial nerves were involved in four patients. There were no asymptomatic patients or patients with visual changes. Of further interest, no

TABLE 2. Clinical Characteristics of 36 Ear and Temporal Bone Meningiomas

\begin{tabular}{lc}
\hline \multicolumn{1}{c}{ Clinical Characteristics } & $\begin{array}{c}\text { Ear/Temporal Bone } \\
\text { Meningiomas }\end{array}$ \\
\hline Gender & 24 \\
Female & 12 \\
Male & \\
Age (in years) & $10-80$ \\
Range & 49.6 \\
Mean & 52.0 \\
Women (mean) & 44.8 \\
Men (mean) & \\
Symptom duration (in months) & $0.5-192$ \\
Range & 24.6 \\
Mean & 16.3 \\
Females (mean) & 41.0 \\
Males (mean) & \\
Symptoms & 20 \\
Hearing changes & 7 \\
Chronic otitis (media or externa) & 5 \\
Headaches and/or otalgia & 4 \\
Mass & 4 \\
Nerve changes (paralysis) & 3 \\
Dizziness/vertigo & 3 \\
Tinnitus & 2 \\
Other (bleeding, cough) & 1 \\
History of trauma & \\
\hline
\end{tabular}

patient reported being part of a kindred with von Recklinghausen's disease or any other phakomatosis. The duration of symptoms ranged from 2 weeks to 192 months, with an average of 24.6 months. The overall long duration of symptoms is most likely related to their nonspecific nature, and the patients were frequently managed without a specific diagnosis. On average, female patients (mean, $16.3 \mathrm{mo}$ ) experienced a shorter duration of symptoms than did male patients (mean, 41.0 mo). However, this difference was not statistically significant. Furthermore, there was a statistically significant difference in the mean duration of symptoms as compared with the anatomic site of distribution: external auditory canal (47.3 mo); middle ear (24.7 mo); temporal bone $(20 \mathrm{mo})$; and mixed locations (7.6 mo; $P$ $=.008)$. This implies that lesions that involve more than one site present with a shorter clinical history.

\section{Radiographic Studies}

Roentgenographic procedures were performed in the majority of patients and included conventional skull radiographs, computed tomography (CT), angiography, and magnetic resonance imaging (MRI). Plain radiographs and CT were used most frequently. A middle-ear mass with diffuse cloudiness suggestive of severe mastoiditis or otitis media was the most frequent radiographic observation. Fluid levels in the air spaces were also identified. Bone destruction or displacement was not noted. Focal bone remodeling was identified by sclerosis or hyperostosis. From a radiographic perspective, no documented central nervous system (CNS) connection was identified in 27 patients, a CNS connection was documented in 2 patients (although after the initial surgery), and a CNS connection was unknown in 7 patients (Table 3). All tumors were centered in the middle ear and/or temporal bone. An MRI scan with a T1-weighted, gadoliniumdiethylenetriamine pentaacetic acid (Gd-DTPA) enhancement was used to underscore the nature of the lesion and the extent of the tumor in the temporal bone region (only in more recent cases). Fourteen patients had radiographic studies interpreted as normal.

\section{Pathologic Features \\ Macroscopic}

The tumors occurred in the middle ear alone ( $n=$ $25)$, external auditory canal only $(n=4)$, temporal bone only ( $n=2)$, and involving the temporal bone, middle ear, and external auditory canal combined ( $n=5$; Table 3 ). Extension into the eustachian tube was documented in one tumor arising from the middle ear. All tumors were unilateral, and the majority affected the right side $(n=25)$. The tumors 
TABLE 3. Macroscopic and Radiographic Findings of $\mathbf{3 6}$ Ear and Temporal Bone Meningiomas

\begin{tabular}{lc}
\hline & $\begin{array}{c}\text { Ear/Temporal Bone } \\
\text { Meningiomas }\end{array}$ \\
\hline Anatomic site & 25 \\
$\quad$ Middle ear & 2 \\
Temporal bone & 4 \\
External auditory canal & 5 \\
Mixed & 1 \\
Extension into eustachian tube & 11 \\
Location & 25 \\
Left & \\
Right & $0.5-4.5$ \\
Size (in cm) & 1.2 \\
Range & \\
Mean & 13 \\
Radiographic presentation & \\
Middle ear or temporal bone mass with & 12 \\
$\quad$ opacification & 2 \\
No bone erosion/invasion & 14 \\
CNS connection present &
\end{tabular}

NOS: not otherwise specified.

ranged in size from 0.5 to $4.5 \mathrm{~cm}$, with a mean size of $1.2 \mathrm{~cm}$. There was a statistically significantly larger size for tumors that arose in the temporal bone (mean, $2.8 \mathrm{~cm}$ ), as opposed to in the external auditory canal (mean, $1.1 \mathrm{~cm}$ ), in the middle ear (mean, $1.1 \mathrm{~cm})$, or in a mixed location $(1.2 \mathrm{~cm} ; P=$ $.02)$. As a result of surgical procedures, the pathologist received the tumors fragmented into small pieces, without an obvious surface epithelium. Lesions from the external auditory canal and middle ear were described as polypoid (Fig. 1). The tumor samples were firm and grayish white to pink.

\section{Microscopic}

The majority ( $n=33$ ) were meningothelial (syncytial) meningiomas (Table 4), composed of lobules of neoplastic cells with indistinct borders and round to oval nuclei with delicate chromatin (Figs. 1, 2). There were 2 psammomatous meningiomas (Fig. 2), although 13 tumors had psammoma bodies. One tumor was classified as atypical meningioma with more than four mitotic figures per 10 high power fields. Intranuclear pseudoinclusions $(n=$ 28; Fig. 3) were identified in both subtypes. Surface epithelium was present in a few tumors. Microscopic bone invasion was present in 10 cases. A particularly remarkable finding was cholesteatoma in association with the meningioma in 9 cases. This finding was not associated with a high recurrence rate: when a cholesteatoma was present, $22.2 \%$ of patients developed a recurrence, whereas $29.6 \%$ of patients without a cholesteatoma developed recurrent tumor.

\section{Immunohistochemical Results}

All lesions tested reacted strongly and diffusely with vimentin (Table 5). The majority exhibited weak and focal reactivity with epithelial membrane antigen (79\%; Fig. 4). Four tumors revealed S-100 protein immunoreactivity, and two, focal immunoreactivity with keratin and CK7, often in a "prepsammomatoid" architecture (Fig. 4). Fifty-six percent demonstrated Ki-67 immunoreactivity ranging from $1+(n=6)$ to $3+(n=3)$, but this affected $<5 \%$ of the nuclei in the specimen. One tumor focally expressed synaptophysin. There was no reactivity with antibodies against glial fibrillary acidic protein, chromogranin, or synuclein.

\section{Treatment and Follow-Up}

All patients were treated by partial or complete surgical excision; complete surgical removal of the tumor was usually not possible as a result of the complex anatomy of the ear and temporal bone. No patients received adjuvant chemotherapy or radiation therapy. Follow-up data was obtained in 35 patients. One patient was lost to follow-up.

Of these 35 patients, 5 had died with local disease (mean, 3.5 years). Four patients were female, and one was male, with tumors involving the middle ear $(n=4)$ or mixed location $(n=1)$. The mean tumor size was $1.6 \mathrm{~cm}$. All meningiomas were meningothelial, and an associated cholesteatoma was noted in one patient. These patients were managed with wide local excision and had from 1 to 4 recurrences between 7 months and 4.8 years. Perhaps a few tumors could be considered residual disease rather than recurrent disease, but we did not make that distinction given the anatomic restrictions of the area and the fact that we are a referral institution (i.e., total gross excision was unknown). Mastoiditis developed in 3 of the 5 patients, seeding the peripheral blood to cause systemic sepsis, which resulted in death. One patient died of myocardial infarction and at autopsy was noted to have residual tumor. The remaining patient died of a stroke but had meningioma present at the skull base and neck.

TABLE 4. Microscopic Features by Tumor Type of 36 Ear and Temporal Bone Meningiomas

\begin{tabular}{lc}
\hline Microscopic characteristic & $\begin{array}{c}\text { Ear/Temporal Bone } \\
\text { Meningiomas }\end{array}$ \\
\hline Subtype & 33 \\
Meningothelial & 2 \\
Psammomatous & 1 \\
Atypical & \\
Architecture & 36 \\
$\quad$ Meningothelial & \\
Growth pattern & 30 \\
$\quad$ Infiltrative & 10 \\
Bone invasion present & 13 \\
Psammoma bodies & 28 \\
Pseudoinclusions & 1 \\
Mitotic figures $>4 / 10 \mathrm{HPF}$ & \\
Associated findings & 9 \\
Cholesteatoma &
\end{tabular}

HPF: high-power field. 


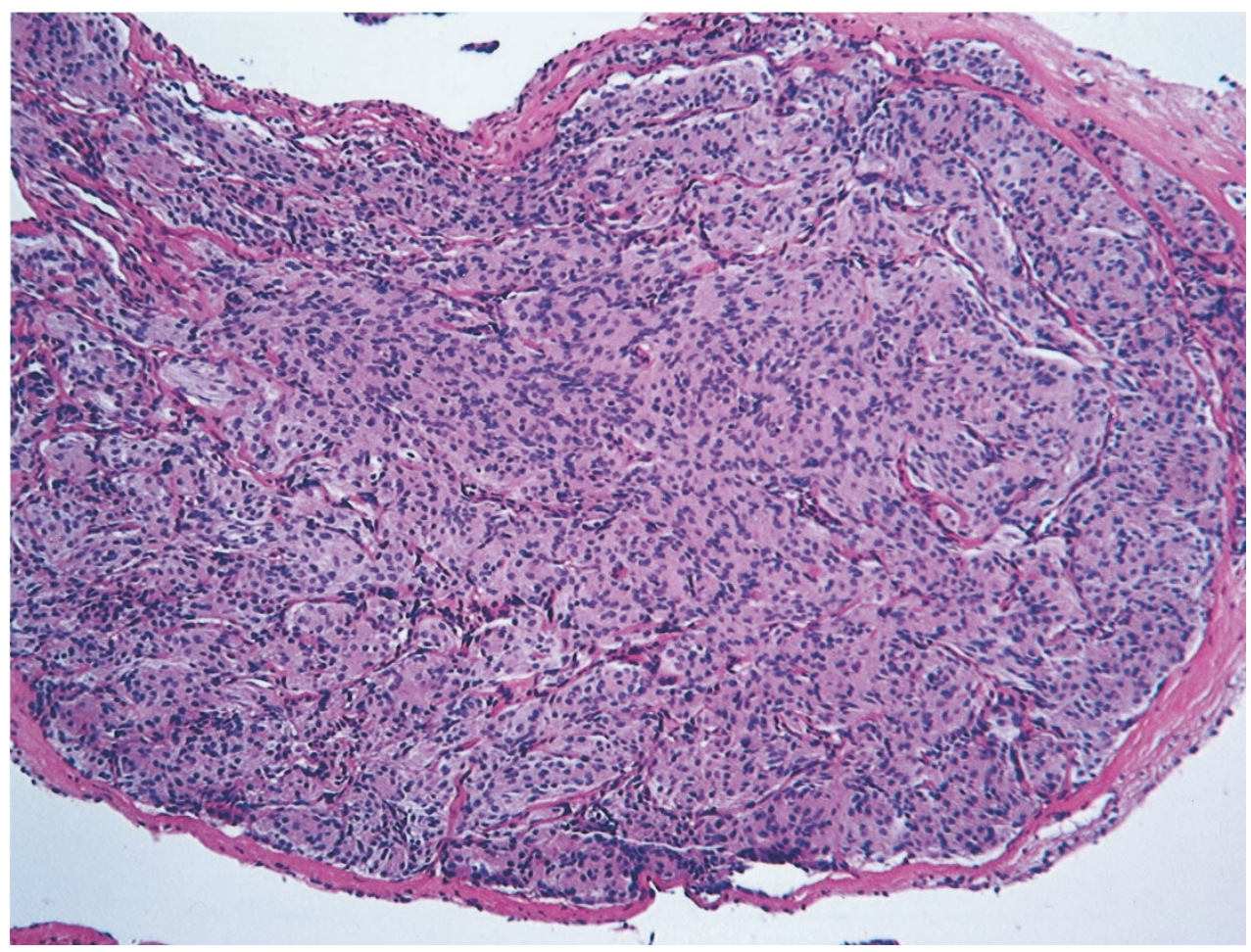

FIGURE 1. Typical meningotheliomatous meningioma with a whorled syncytial architecture growing in a polypoid fashion in this low-power image.

The remaining 30 patients were alive $(n=25$, mean $=19.0$ years) or had died of unrelated causes ( $n=5$, mean $=9.5$ years) without evidence of tumor (range, 1.4-23.6 years). This yielded a raw 5-year survival rate of $80 \%$; a 5 -year disease-free survival rate of $77.1 \%$; a raw 10 -year survival rate of $68.6 \%$; and a 10 -year disease-free survival rate of $68.6 \%$. We conclude that if the patients did not have
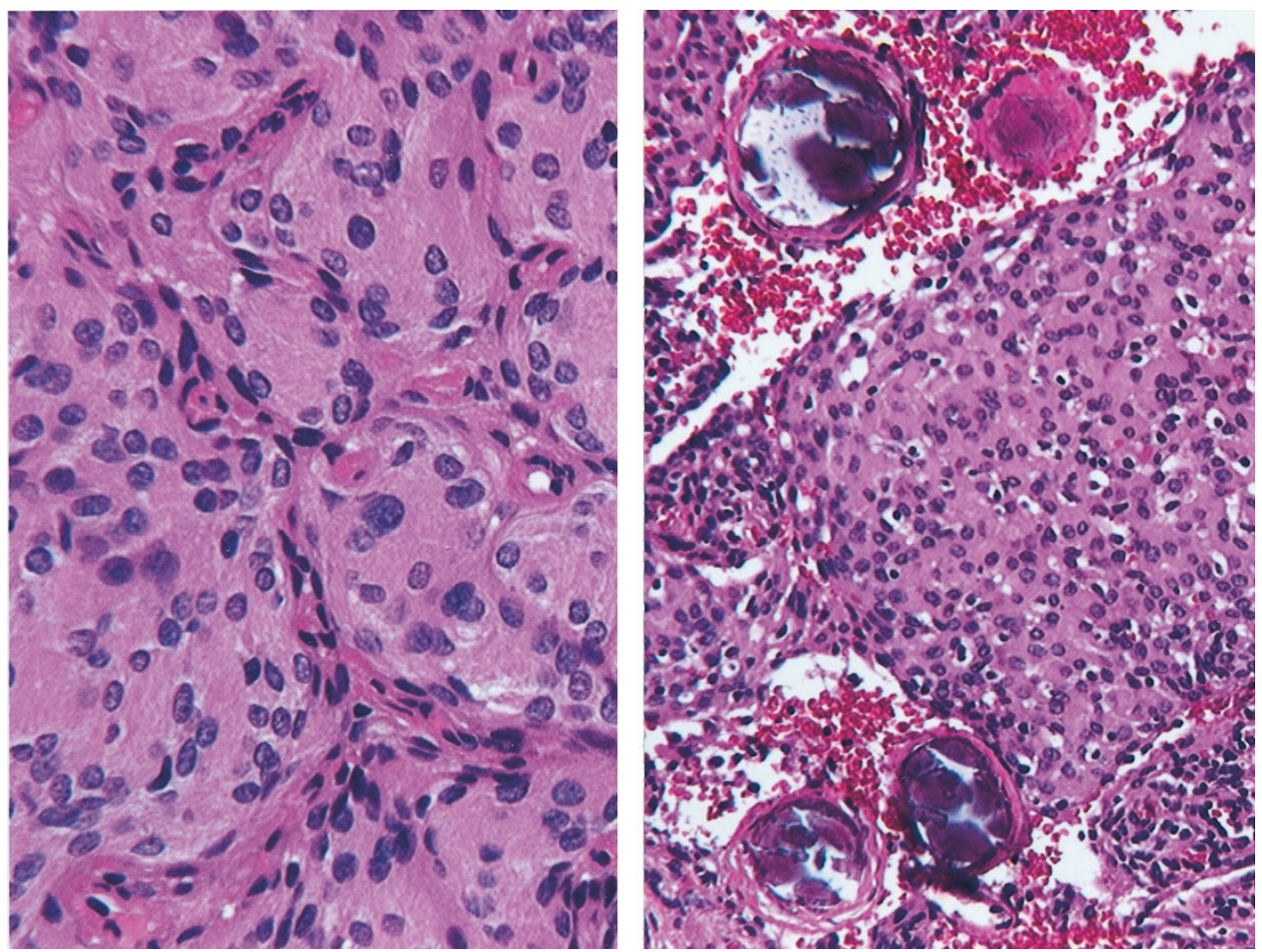

FIGURE 2. Whorled architecture is maintained, with the meningothelial cells having indistinct borders and delicate nuclear chromatin. Psammoma bodies are identified in many cases. 

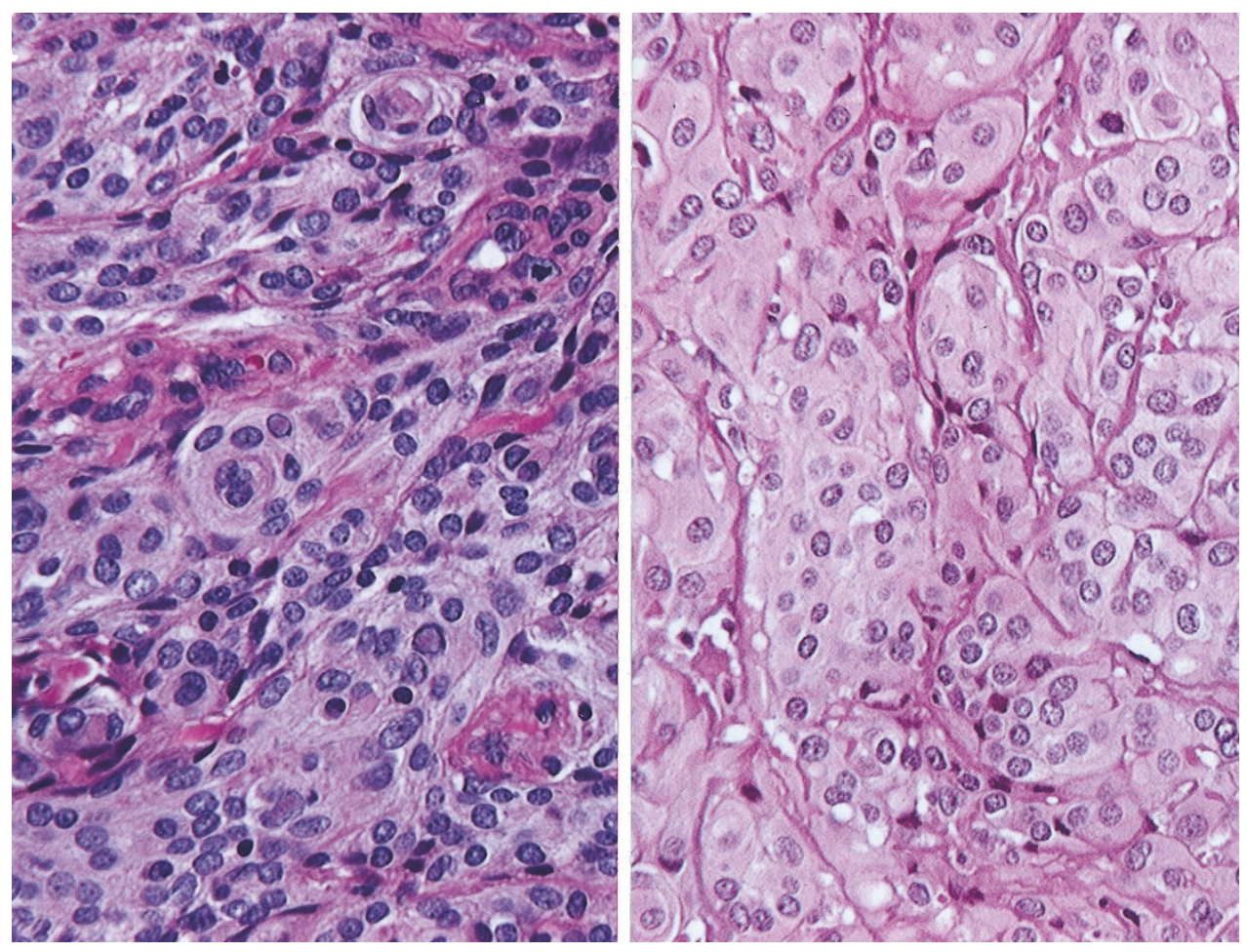

FIGURE 3. A variety of different growth patterns can be seen, but the meningothelial nature of the neoplasm is always maintained. Intranuclear cytoplasmic inclusions are seen (left), along with a paraganglioma-like growth $(\boldsymbol{r i g h t})$.

recurrent disease within 5 years, their survival was excellent.

Ten patients developed local recurrence ranging from 5 months to 4.8 years after the initial presen- tation. The 2 patients who developed tumor within 5-9 months after original surgery were interpreted to probably represent residual disease after incomplete excision because the tumors were present

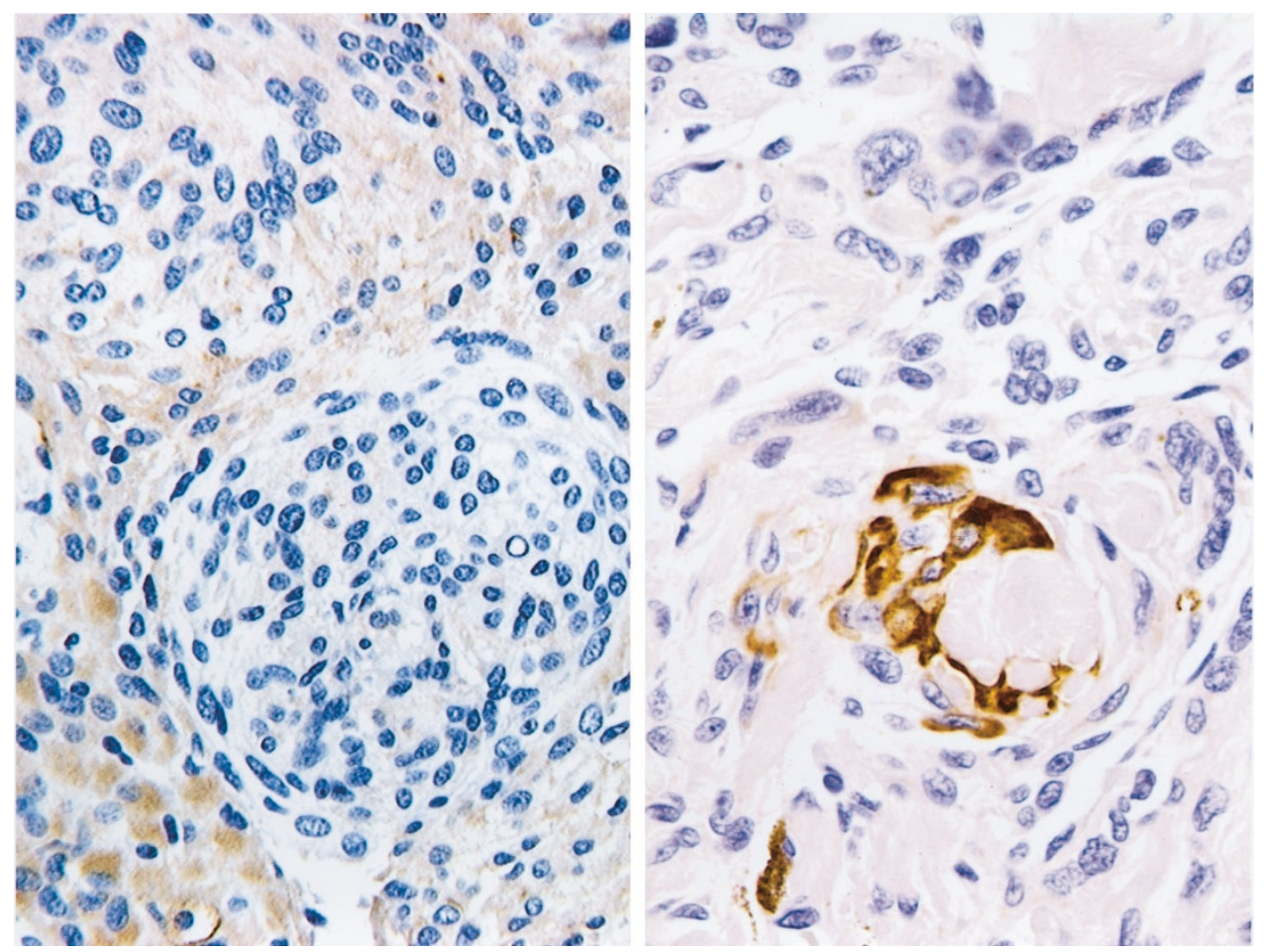

FIGURE 4. Epithelial membrane antigen reactivity was usually weak and focal (left), whereas CK 7 was immunoreactive in a "pre-psammoma body"-like distribution. 


\begin{tabular}{lc}
\hline \multicolumn{1}{c}{ Antibody } & $\begin{array}{c}\text { Number of } \\
\text { Cases with } \\
\text { Positive } \\
\text { Reactions }\end{array}$ \\
\hline Epithelial membrane antigen (EMA) & $15 / 19(78.9 \%)$ \\
Glial fibrillary acidic protein (GFAP) & 0 \\
S-100 protein & $4 / 18(22.2 \%)$ \\
Vimentin & $19 / 19(100 \%)$ \\
Cytokeratin (AE1/AE3 and CK1) & $2 / 18(11.1 \%)$ \\
CAM5.2 & $1 / 16(6.3 \%)$ \\
CK20 & 0 \\
CK7 & $2 / 16(12.5 \%)$ \\
Chromogranin & 0 \\
Synaptophysin & $1 / 18(5.5 \%)$ \\
Synuclein & 0 \\
Ki67 & $9 / 16(56.3 \%)$ \\
\hline
\end{tabular}

within a few months of the initial resection and it is often difficult to obtain tumor-free surgical margins. The remaining recurrences were present at the same site as the previous tumor, although usually those in the recurrence specimen were more infiltrative. Of these 8 patients with recurrent disease, 5 had died with disease (mean, 3.5 years), whereas the remaining 3 were alive without evidence of disease (mean, 16.3 years). The specific site of origin (Table 6), patient gender, presence of bone invasion, histologic type, presence of a cholesteatoma, or an increased percentage of Ki-67 immunoreactive cells did not alter the long-term patient outcome.

\section{DISCUSSION}

Arachnoid cells (arachnoid granulations, meningocytes, meningothelial cells, pacchionian bodies) are thought to arise from neural crest. They normally line the inner aspect of the arachnoid membrane and fill the cores of the arachnoid villi that project into the lumens of dural veins and venous sinuses. Increasing evidence supports the development of meningiomas from arachnoid cap cells, with different mechanisms to suggest how extracranial meningiomas arise. In the ear or mastoid bone specifically, an intracranial meningioma can extend by the path of least resistance and follow the tegmen tympani (through dehiscence), the sulci of the greater and lesser superficial petrosal nerves, the posterior fossa plate (geniculate ganglion area), the internal auditory canal (porus internus, lateral semicircular canal, or perilabyrinthine cell tracts), or the jugular foramen by direction extension, origination from arachnoid cell clusters in the sheaths of cranial nerves or vessels as they exit foramina or suture lines of the skull, or without any apparent demonstrable connection to the CNS $(8,10,12,18$, $23,27,31,35,39,45-56)$. Arachnoid cells are identified outside the neuraxis, thereby giving rise to meningiomas in the ear and temporal bone.

Up to $20 \%$ of intracranial meningiomas may have extraneuraxial extension $(3,36,38,45-47,55)$, including the skull, scalp (all cutaneous sites), orbit, upper airway involvement (nasal cavity, paranasal sinuses, nasopharynx), soft tissues, and ear and temporal bone. However, when the scalp, orbit, sinonasal tract, oral cavity, and soft tissues are excluded, the incidence decreases to $<1 \%(9,35,36$, $46,51,55,57-59)$. Primary ear and temporal bone meningiomas made up only $2.0 \%$ of the benign or malignant primary ear and temporal bone tumors seen in consultation at the AFIP during the period of study. This information further supports the rare nature of this neoplasm in the ear and temporal bone.

Most of the reported cases involving the ear and temporal bone represent secondary extension from an intracranial lesion $(2-19,21-38,46,47)$. Extracranial meningiomas arising from the ear and temporal bone (middle ear, tympanic membrane, and external ear canal specifically), without any evidence of an association with an intracranial tumor (also called heterotopic, ectopic, or extracal-

TABLE 6. Patient Outcome for 36 Ear and Temporal Bone Meningiomas (mean years of follow-up)

\begin{tabular}{|c|c|c|c|c|}
\hline & $\begin{array}{c}\text { All } \\
\text { Patients* }\end{array}$ & A, NED & D, NED & $\mathrm{D}, \mathrm{D}$ \\
\hline All patients with follow-up & 35 (15.5) & $25(19.0)$ & $5(9.5)$ & $5(3.5)$ \\
\hline Follow-up range & $1.4-31.5$ & $4.8-31.5$ & $1.4-23.6$ & $1.9-5.9$ \\
\hline Patients with recurrence & $10(10.4)$ & $5(17.2)$ & $\mathrm{n} / \mathrm{a}$ & $5(3.5)$ \\
\hline \multicolumn{5}{|l|}{ Anatomic site } \\
\hline Middle ear alone & $25(16.6)$ & $19(20.2)$ & $2(8.3)$ & $4(3.3)$ \\
\hline All other sites* & $10(12.7)$ & $6(15.3)$ & $3(10.4)$ & $1(4.2)$ \\
\hline \multicolumn{5}{|l|}{ Specific feature } \\
\hline Female patients* & $23(16.5)$ & $17(20.7)$ & $2(8.0)$ & $4(2.9)$ \\
\hline Male patients & $12(13.5)$ & $8(15.6)$ & $3(10.6)$ & $1(5.9)$ \\
\hline Bone invasion present & $10(15.9)$ & $6(18.4)$ & $2(19.1)$ & $2(5.0)$ \\
\hline Cholesteatoma present & $9(14.0)$ & $8(15.2)$ & $\mathrm{n} / \mathrm{a}$ & $1(4.2)$ \\
\hline Atypical histology & $1(16.8)$ & $1(16.8)$ & $\mathrm{n} / \mathrm{a}$ & $\mathrm{n} / \mathrm{a}$ \\
\hline Ki67 immunoreactive & $9(13.5)$ & $7(18.6)$ & $1(2.0)$ & $2(3.9)$ \\
\hline Ki67 non-immunoreactive & $7(10.6)$ & 4 (16.7) & $1(1.4)$ & $2(3.1)$ \\
\hline
\end{tabular}

A, NED: alive, no evidence of disease; A, WD: alive, with disease; D, NED: Dead, no evidence of disease; D, D: dead, with disease; n/a: not applicable; *: one patient was lost to follow-up; NOS: not otherwise specified. 
varial), are rare $(2,4,5,7,9-12,14-17,19,29,32$, 36 ), and most of the reported cases were published before modern radiographic imaging techniques were available to exclude intracranial tumor. Whereas two of our cases demonstrated an intracranial component, whether radiographically, at surgery, or in postoperative workup, 34 cases were diagnosed as primary ectopic meningiomas of the ear and temporal bone, based on a lack of clinical, radiographic, operative, or follow-up data to support an intracranial lesion. Therefore, one cannot be absolutely certain as to the point of origin of ear and temporal bone meningiomas. Although autopsy examination failed to disclose an intracranial primary in 6 of the 10 patients who died, the distinct possibility of an intracranial fraction must always be considered $(8,27,28,45,54)$.

In this series, ear and temporal bone meningiomas were not only more common in female than male patients (ratio of 2:1), but female patients were also significantly older (mean, 52 years) than male patients (mean, 45 years; $P=.01 ; 2,11,27,47$, $60)$. The average age at presentation of our patients (49.6 years) was not different from the middle-aged figure used for intracranial meningiomas without any extracranial extension. No patients in this clinical series had any syndrome-associated meningiomas, although such patients have been reported elsewhere (61).

Symptoms were nonspecific for the patients reported in the literature and for our patients, with progressive hearing loss (either sensorineural or conductive-type hypoacusis) recounted most often. Because of the rarity of these tumors and their nonspecific clinical and radiographic features, it is not surprising that the average duration of clinical symptoms in this series was 24.6 months, similar to that for the patients reported in the literature, with a number of patients experiencing symptoms for $>10$ years $(2,9,47)$. Therefore, a correct diagnosis of ear and temporal bone meningiomas cannot be made without histologic evaluation, especially because the roentgenographic findings are usually nonspecific (62). Nearly half of the patients had radiographic images interpreted as "normal," suggesting that the tumor can be quite small. Highresolution scanning is probably requisite for an accurate determination of the extent of the tumor. Meningiomas often show a proclivity for local permeation of crevices, suture lines, and foramina of the skull $(25,35,49,55,62)$. It may be difficult to demonstrate an intracranial component to the meningioma, especially if there is a clinically silent (asymptomatic) or a radiographically obscure en plaque growth, which creates a small dural or intracranial component while the bulk of the tumor grows beyond the cranial vault. However, GdDTPA-enhanced MRI has a much higher sensitivity for meningiomas than does CT $(20,25,28,35,49$, $62,63)$.

Like their intracranial counterparts, ear and temporal bone meningiomas may exhibit a variety of different histologic patterns even though most cases in this series were meningothelial or psammomatous meningiomas. One tumor was classified as atypical meningioma based on mitotic activity of more than four per 10 high-power fields, but this patient did not develop recurrence and is alive 16.8 years later, without evidence of disease. The differential diagnosis of ear and temporal bone meningiomas includes a variety of benign and malignant neoplasms, with paraganglioma and schwannoma the most frequent misdiagnoses (64). The general histologic features and immunohistochemical findings can usually differentiate between these tumors. Paragangliomas have an organoid growth pattern, with clear to basophilic cytoplasm surrounding hyperchromatic nuclei and a distinctive immunoprofile (chromogranin-positive paraganglia cells and S-100 protein-positive sustentacular cells). A meningocele can occur in the middle ear and temporal bone, but histologically they are cystic, have a connection to the central nervous system, and are usually congenital or "acquired" after surgery, infection, or trauma $(59,65)$. A neuroendocrine adenoma of the middle ear has a more organoid growth, with neuroendocrine nuclear features and strong keratin, chromogranin, and human pancreatic polypeptide immunoreactivity (66). The immunohistochemical profile of ear and temporal bone meningiomas was indistinguishable from that of intracranial lesions, with vimentin, epithelial membrane antigen, and S-100 protein immunoreactivity. The degree of cellular proliferation, as assessed by immunostaining with Ki-67, was extremely variable. The cases that were immunoreactive tended to be strongly reactive, but only in a few nuclei. The overall proliferation index was unrelated to prognosis and therefore does not seem valuable in the workup of ear and temporal bone meningiomas (67-69).

In general, the prognosis of primary meningiomas of the ear and temporal bone appears to be excellent, with an overall raw survival of 15.5 years (Table 6; 2). The recurrence rate for meningiomas after total excision varies from $7-84 \%$, depending on the number of years of follow-up $(2,18,46,70)$, with our rate of $28 \%$ falling within this range. This is similar to the case of intracranial meningiomas, which have a recurrence rate of $\leq 20 \%$ and a mean survival of around 7 years $(46,70)$. In our study, there was little difference between the 5-year and 10 -year disease-free survival rates $(82.1 \%$ versus $78.6 \%$, respectively), indicating that once the patients had been disease free for 5 years, they were unlikely to die with tumor. This finding is different 
from the case of meningiomas in general, in which the recurrence rate increases with protracted follow-up (6\% recurrence at 5 years and $20 \%$ recurrence at 15 years; 70). Either finding supports the insidious, slow, indolent but still aggressive growth of ear and temporal bone meningiomas. Therefore, meticulous surgical extirpation of primary ear and temporal bone meningiomas is important to minimize the recurrence rate, without the necessity of adjuvant therapy. Although surgery is the treatment of choice, there are a number of challenges because of the invasiveness of the tumors and the complexity of the anatomy of the ear and temporal bone, especially if cranial nerve function and hearing preservation is intended. Therefore, it probably is best to use a multidisciplinary approach with a combination of intracranial, temporal bone (subtemporal, translabyrinthine, or transcochlear), and skull base (suboccipital) techniques to achieve total resection, possibly including widely exenterative procedures to achieve this end $(12,13,18,21,71)$. Although none of the patients in this series received radiation therapy, such therapy has been suggested to yield a possible improvement in survival in cases of meningioma of the central nervous system (72). Additional analysis of ear and temporal bone meningiomas would be necessary before this trend toward improved survival with radiation therapy can be confirmed.

Metastatic dissemination of these meningiomas did not occur in any of our patients, nor did we find any convincing cases in the literature. Based on this series and a review of the literature, none of the clinical, radiographic, or pathologic features correlated with patient outcome, although female patients did tend to develop recurrent disease more frequently. If death with tumor does result, it is usually the result of involvement of the vital structures of the ear and temporal bone region or complications of the surgery, rather than the aggressive nature of the tumor.

In summary, ear and temporal bone meningiomas are uncommon tumors whose clinical and radiographic features are nonspecific, and consequently an accurate diagnosis requires histologic evaluation. Females are affected more frequently than males and in general offer initial presentation at an older age, with hearing loss. Histologically and immunophenotypically, ear and temporal bone meningiomas are indistinguishable from their intracranial counterparts, but an awareness of these characteristic pathologic and immunohistochemical features should allow distinction from paraganglioma and schwannoma. Complete surgical eradication of the neoplasm will yield the best longterm clinical outcome, although recurrences occur in $\leq 20 \%$ of cases.
Acknowledgments: The authors thank Dr. Dennis K. Heffner for his critical review of the manuscript and Harold Lindmark for his excellent research assistance.

\section{REFERENCES}

1. Burger PC, Scheithauer BW. Tumors of meningothelial cells. In: Tumors of the central nervous system. 3rd series ed. Washington, DC: Armed Forces Institute of Pathology; 1994. p. $259-86$

2. Maniglia AJ. Intra and extracranial meningiomas involving the temporal bone. Laryngoscope 1978;88:1-58.

3. Buehrle R, Goodman WS, Wortzman G. Meningioma of the temporal bone. Can J Otolaryngol 1972;1:16-20.

4. Chen KTK, Dehner LP. Primary tumors of the external and middle ear. Arch Otolaryngol 1978;104:253-9.

5. DeWeese DD, Everts EC. Primary intratympanic meningioma. Arch Otolaryngol Head Neck Surg 1972;96:62-6.

6. Divis BO, Ruby RR. Petrous meningioma en plaque presenting as a right middle ear tumor. J Otolaryngol 1976;5:227-32.

7. El-Ghazali TM. Primary intra-tympanic meningioma. J Laryngol Otol 1981;95:849-52.

8. Friedman RA, Nelson RA, Harris JP. Posterior fossa meningiomas intimately involved with the endolymphatic sac. Am J Otol 1996;17:612-6.

9. Granich MS, Pilch BZ, Goodman ML. Meningiomas presenting in the paranasal sinuses and temporal bone. Head Neck Surg 1983;5:319-28.

10. Guzowski J, Paparella MM, Nageswara K, Hoshino T. Meningiomas of the temporal bone. Laryngoscope 1976;86:1141-6.

11. Haught K, Hogg JP, Killeffer JA, Voelker JL, Schochet SS. Entirely intracanalicular meningioma: contrast-enhanced MR findings in a rare entity. Am J Neuroradiol 1998;19: 1831-3.

12. Hooper R, Siu K, Cousins V. Temporal bone meningiomas. Aust N Z J Surg 1990;60:779-86.

13. Ishikawa N, Komatsuzaki A, Tokano H. Meningioma of the internal auditory canal with extension into the vestibule. J Laryngol Otol 1999;113:1101-3.

14. Karam FK, Salman SD. Meningioma of the ear. Arch Otolaryngol Head Neck Surg 1964;80:177-9.

15. Kelleher RJ, Murray JAM, Welsby PD. Recurrent meningitis associated with meningioma of the mastoid cavity. J Laryngol Otol 1989;103:99-100.

16. Kumar A, Mafee M, Vassalli L, Applebaum EL. Intracranial and intratemporal meningiomas with primary otologic symptoms. Otolaryngol Head Neck 1988;99:444-54.

17. Kuzeyli K, Duru S, Baykal S, Usul H, Ceylan S, Akturk F. Primary intraosseous meningioma of the temporal bone in an infant. A case report. Neurosurg Rev 1996;19:197-9.

18. Langman AW, Jackler RK, Althaus SR. Meningioma of the internal auditory canal. Am J Otol 1990;11:201-4.

19. Martinez-Devesa PM, Wareing MJ, Moffat DA. Meningioma in the internal auditory canal. J Laryngol Otol 2001;115:48-9.

20. Moulin G, Coatrieux A, Gillot JC, Chagnaud C, Bartoli JM, Pech A, et al. Plaque-like meningioma involving the temporal bone, sinonasal cavities and both parapharyngeal spaces: CT and MRI. Neuroradiology 1994;36:629-31.

21. Nassif PS, Shelton C, Arriaga M. Hearing preservation following surgical removal of meningiomas affecting the temporal bone. Laryngoscope 1992;102:1357-62.

22. O'Reilly RC, Kapadia SB, Kamerer DB. Primary extracranial meningioma of the temporal bone. Otolaryngol Head Neck Surg 1998;118:690-4.

23. Ohta S, Yokoyama T, Uemura K, Nishizawa S, Yamamoto S, Hoshino T. Petrous bone meningioma originating from the 
jugular foramen-case report. Neurol Med Chir (Tokyo) 1997;37:472-4.

24. Oro J, Estrem S. Transpetrosal approach to meningiomas of the medial temporal bone. Mo Med 1994;91:357-9.

25. Parisier SC, Som PM, Shugar JM, Marovitz WF. The evaluation of middle ear meningiomas using computerized axial tomography. Laryngoscope 1978;88:1170-7.

26. Prayson RA. Middle ear meningiomas. Ann Diagn Pathol 2000;4:149-53.

27. Rietz DR, Ford CN, Kurtycz DF, Brandenburg JH, Hafez GR. Significance of apparent intratympanic meningiomas. Laryngoscope 1983;93:1397-404.

28. Rosencrantz M, Stattin S. Extradural meningiomas. Report of two cases. Acta Radiol Diag (Stockh) 1972;12:419-27.

29. Salama N, Stafford N. Meningiomas presenting in the middle ear. Laryngoscope 1982;92:92-7.

30. Salvinelli F, Trivelli M, Greco F, Linthicum FH. Acoustic neuromas and meningiomas. Histopathological aspect: a post mortem study on temporal bones. Eur Rev Med Pharmacol Sci 1999;3:221-4.

31. Shuangshoti S, Panyathanya R. Ectopic meningiomas. Arch Otolaryngol 1973;98:102-5.

32. Singh KP, Smyth GDL, Allen IV. Intracanalicular meningioma. J Laryngol Otol 1975;89:549-52.

33. Taylor JS, Crocker PV, Keebler JS. Middle ear meningioma: case report. Ala Med 1989;58:17-8.

34. Tsunoda R, Fukaya T. Extracranial meningioma presenting as a tumour of the external auditory meatus: a case report. J Laryngol Otol 1997;111:148-51.

35. Waga S, Nishikawa M, Ohtsubo K, Kamijyo Y, Handa H. Extracalvarial meningiomas (2 cases). Neurology 1970;20: 368-72.

36. Whicker JH, Devine KD, MacCarty CS. Diagnostic and therapeutic problems in extracranial meningiomas. Am J Surg 1973;126:452-7.

37. Zeitouni AG, Zagzag D, Cohen NL. Meningioma of the internal auditory canal. Ann Otol Rhinol Laryngol 1997;106:657-61.

38. Brookler KH, Hoffman RA, Camins M, Terzakis J. Trilobed meningioma: ampulla of posterior semicircular canal, internal auditory canal, and cerebellopontine angle. Am J Otol 1980;1:171-3.

39. Chang CY, Cheung SW, Jackler RK. Meningiomas presenting in the temporal bone: the pathways of spread from an intracranial site of origin. Otolaryngol Head Neck Surg 1998; 119:658-64.

40. Kleihues P, Cavenee WK. Pathology and genetics of tumours of the nervous system. 3rd ed. Lyon, France: IARC Press, 2000.

41. Perry A, Scheithauer BW, Stafford SL, Lohse CM, Wollan PC. "Malignancy" in meningiomas: a clinicopathologic study of 116 patients, with grading implications. Cancer 1999;85: 2046-56.

42. Perry A, Stafford SL, Scheithauer BW, Suman VJ, Lohse CM. Meningioma grading. An analysis of histologic parameters. Am J Surg Pathol 1997;21:1455-65.

43. de la Monte SM, Flickinger J, Linggood RM. Histopathologic features predicting recurrence of meningiomas following subtotal resection. Am J Surg Pathol 1986;10:836-43.

44. Hsu SM, Raine L, Fanger H. Use of avidin-biotin-peroxidase complex (ABC) in immunoperoxidase techniques: a comparison between $\mathrm{ABC}$ and unlabeled antibody (PAP) procedures. J Histochem Cytochem 1981;29:577-80.

45. Batsakis JG. Pathology consultation. Extracranial meningiomas. Ann Otol Rhinol Laryngol 1984;93:282-3.

46. Civantos F, Ferguson LR, Hemmati M, Gruber B. Temporal meningiomas presenting as chronic otitis media. Am J Otol 1993;14:403-6.

47. Nager GT, Heroy J, Hoeplinger M. Meningiomas invading the temporal bone with extension to the neck. Am J Otolaryngol 1983;4:297-324.
48. Hoye SJ, Hoar CS Jr, Murray JE. Extracranial meningioma presenting as a tumor of the neck. Am J Surg 1960;100:486-9.

49. Siegel GJ, Anderson PJ. Extracalvarial meningioma. Case report. J Neurosurg 1966;25:83-6.

50. Lopez DA, Silvers DN, Helwig EB. Cutaneous meningiomas. A clinicopathologic study. Cancer 1974;34:728-44.

51. Miyamoto T, Mihara M, Hagari Y, Shimao S. Primary cutaneous meningioma on the scalp: report of two siblings. J Dermatol 1995;22:611-9.

52. Wolff M, Randow RM. Meningioma of the parotid gland. An insight into the pathogenesis of extracranial meningioma. Hum Pathol 1971;2:453-9.

53. Thompson LD, Gyure KA. Extracranial sinonasal tract meningiomas: a clinicopathologic study of 30 cases with a review of the literature. Am J Surg Pathol 2000;24:640-50.

54. Friedman CD, Costantino PD, Teitelbaum B, Berktold RE, Sisson GA. Primary extracranial meningiomas of the head and neck. Laryngoscope 1990;100:41-8.

55. Farr HW, Gray GF Jr, Vrana M, Panio M. Extracranial meningioma. J Surg Oncol 1973;5:411-20.

56. Bain GO, Shnitka TK. Cutaneous meningioma (psammoma). Report of a case. Arch Dermatol 1956;74:590-4.

57. Wolman L. The extracranial spread of meningioma. Eye Ear Nose Throat Digest 1969;46-57.

58. Brown AM, Fordham KC, Lally ET. Meningioma presenting as an intraoral mass. Oral Surg Oral Med Oral Pathol 1976; 41:771-6.

59. Simpson MT, Sneddon KJ. Extracranial meningioma of the oral cavity. Br J Oral Maxillofac Surg 1987;25:520-5.

60. D'Angelo AJ, Marlowe A, Marlowe FI, Mobini J. Primary meningiomas of the middle ear: do they exist? Ear Nose Throat J 1991;70:794-8.

61. Evard M, Passy V. Von Recklinghausen's disease with multiple meningiomas. Laryngoscope 1972;82:2222-5.

62. Geoffray A, Lee YY, Jing BS, Wallace S. Extracranial meningiomas of the head and neck. Am J Neuroradiol 1984;5:599-604.

63. Wagle VG, Glickstein M. Role of MRI in meningiomas: with and without Gadopentetate. Conn Med 1990;54:485-91.

64. Kepes J, Kernohan JW. Meningiomas: problems of histological differential diagnosis. Cancer 1959;12:364-70.

65. Gyure KA, Thompson LD, Morrison AL. A clinicopathological study of 15 patients with neuroglial heterotopias and encephaloceles of the middle ear and mastoid region. Laryngoscope 2001;110:1731-5.

66. Torske KR, Thompson LDR. Adenoma versus carcinoid tumor of the middle ear. A study of 48 cases and review of the literature. Mod Pathol 2002;15:543-55.

67. Hsu DW, Pardo FS, Efird JT, Linggood RM, Hedley-Whyte ET. Prognostic significance of proliferative indices in meningiomas. J Neuropathol Exp Neurol 1994;53:247-55.

68. Langford LA. Pathology of meningiomas. J Neurooncol 1996; 29:217-21.

69. Matsuno A, Nagashima T, Matsuura R, Tanaka H, Hirakawa M, Murakami M, et al. Correlation between MIB-1 staining index and the immunoreactivity of p53 protein in recurrent and nonrecurrent meningiomas. Am J Clin Pathol 1996;106:776-81.

70. Mirimannoff RO, Dosoroetz DE, Linggood RM, Ojemann RG, Martuza RL. Meningioma: analysis of recurrence and progression following neurosurgical resection. J Neurosurg 1985;62:18-24.

71. Pensak ML, Van Loveren H, Tew JM, Keith RW. Transpetrosal access to meningiomas juxtaposing the temporal bone. Laryngoscope 1994;104:814-20.

72. Stafford SL, Perry A, Suman VJ, Meyer FB, Scheithauer BW, Lohse CM, et al. Primarily resected meningiomas: outcome and prognostic factors in 581 Mayo Clinic patients, 1978 through 1988. Mayo Clin Proc 1998;73:936-42. 